\title{
Da casa da palavra ao olho da rua: a crônica como uma narrativa urbana
}

\author{
Jeana Laura da Cunha Santos ${ }^{1}$ \\ Universidade Federal de Santa Catarina, Santa Catarina, Brasil \\ E-mail: jeanasantos@terra.com.br
}




\section{Resumo}

No presente artigo, a proposta é trazer à tona um instante pioneiro de passagem do espaço privado para o público mediado pela perspectiva de alguns dos nossos primeiros jornalistas como Machado de Assis e Olavo Bilac. Tais autores transpuseram o espaço hermético do livro a Casa da palavra para se consagrarem no "olho da rua", representado pela literatura urbana do jornal. Nessa travessia, surge a crônica, gênero de passagem que retrata tipos, fatos, modas, costumes e espaços urbanos no Rio de Janeiro da virada do século XIX para o século XX, cidade que abarca parte importante do imaginário nacional e que inauguraria um ethos presente até os dias atuais.

Palavras-chave: Antropologia urbana. Narrativa urbana. Literatura. Jornalismo.

\section{Abstract}

In the present article, the author proposes to bring up a pioneer instant of passage of the private space for the public space mediated for the perspective of some of our first journalists as Machado de Assis and Olavo Bilac. Such authors had transposed the airtight space of the book, the "house of the word", to consecrate themselves in the "eye of the street", represented for the urban literature of the journal. In this crossing, it appears the chronicle, sort of passage that portraies types, urban facts, customs, spaces in Rio de Janeiro of the turn of century 19th for the 20th, city this that monopolizes important part of the national imaginary and that it would inaugurate a ethos present until the current days.

Keywords: Urban anthropology. Urban narrative. Literature. Journalism. 


\section{A cidade como fonte de alegorias}

e hoje ir às ruas, andar a passeio, distrair-se com as mercadorias $\mathcal{O}$ expostas nas vitrines translúcidas e com os outdoors cada vez mais luminosos e apelativos é um fenômeno urbano comum na experiência do habitante da cidade moderna, nem sempre fora assim.

Houve um tempo em que habitar as ruas era algo novo e estranho e o citadino que se aventurasse a ensaiar esses primeiros passos o fazia com um misto de medo e encantamento. Conforme Benjamin (1994), o medo refletia-se na atitude que a burguesia tinha em buscar uma compensação pelo desaparecimento dos vestígios da vida privada na cidade grande apropriando-se cada vez mais de seus artigos e acessórios caseiros, fixando sua marca nos objetos, enfeitando-os, cobrindo-os, tornando a casa um reduto apropriado contra a ameaça da perda de identidade. Para Martin-Barbero (1997), a residência é o local onde o burguês se refugia na tentativa de conservar para si, e como parte de si, o passado. "Daí que seja no interior onde o burguês dará asilo à arte, e que seja nela onde busca conservar suas pegadas" (Martin-Barbero, 1997, p. 77-78).

Mas, paradoxalmente, o medo passou a ceder lugar à vontade de se sair às ruas enigmáticas, uma vez que a casa burguesa do início do século XX, nas grandes cidades, tornou-se também a sede de uma crise emergente. Para Morin (1977), o desalojamento do indivíduo da casa burguesa confirma a crise nos modelos integrados e integradores. De ilhota de harmonia,

[...] pequeno paraíso de conforto, de bem-estar, de status, lindamente decorado e arrumado", a casa tornase também a sede de uma crise emergente, onde nos 
deparamos com aquele com o qual não sabemos mais conviver: nós mesmos (Morin, 1977, p. 111 ).

O sujeito moderno isola-se como nunca no seio da massa, da multidão. Para Benjamin, “[...] ela (a massa) jaz como um véu à frente do flâneur: é a última droga do ser isolado. [...] ela apaga todos os vestígios do indivíduo: ela é o mais novo asilo do proscrito" (Benjamin, 1994, p. 224). O lugar adequado para o sujeito coletivo? A cidade, onde qualquer indivíduo apaga as pistas que poderiam revelar a sua identidade.

Único campo válido da experiência moderna, a cidade é corpo onde se inscrevem emoções e paixões, experiências intransmissíveis e singulares que o poeta-alegorista canta. A cidade é um mundo em miniatura - mônada da modernidade, e como toda mônada benjaminiana é cristalização de tensões: passagem de um espaço flutuante entre o interior e o exterior das Passagens, o real e o irreal, a desvalorização mercantil de tudo e a nova aura do imprevisto (Matos, 1989, p. 72, grifos da autora).

Como se vê, a cidade acolhe o despedaçamento do sujeito moderno, sua necessidade de adaptar-se à aceleração, às rotinas de trabalho e à fragmentação do olhar. A cidade, sob o olhar do habitante moderno, é um espaço psíquico em que os efeitos de choque vão transformando todo um modo de viver e de sentir. Entender essa transformação é procurar desvendar e compreender como a

[...] experiência de viver nas grandes cidades modernas, planejadas em função dos novos fluxos energéticos e marcadas pela onipresença das novas técnicas, influencia e altera drasticamente a sensibilidade e os estados de disposição de seus habitantes (Sevcenko, 1998, p. 522).

Na cidade moderna, de um lado, o olhar perde a capacidade de olhar, os gestos ficam automáticos, os indivíduos viram autômatos em sua uniformidade de roupas e gestos. "A perda da capacidade do olhar significa dissolução do sujeito: não há mais sujeito em um mundo no qual as leis de mercado regem a vida de cada um, mesmo daquele que parecia escapar: o poeta" (Matos, 1989, p. 73-74). Não há mais garantia nas formas transcendentes ou na imanência do eu cartesiano e 
[...] passa-se, hoje, da construção do sujeito à sua dissolução, o que transparece, em Benjamin, nas análises da grande metrópole, universo fugidio de onde estão ausentes referências estáveis e origem: falta-nos um lugar de retorno (Matos, 1993, p. 113, grifos da autora).

O que se perde, segundo a autora, é, sobretudo, a referência visual, e o elemento "vidro" nas grandes cidades alegoriza bem a condição de passagem entre interior/exterior e a transparência de um olhar que enxerga sem ver. O olhar de quem habita a cidade é um olhar melancólico, que se encanta e desencanta a um só tempo com o que vê.

Por uma reversão de sentido, é justamente esse não lugar que acolheria a identidade perdida de quem se sente desalojado da casa. A cidade fascina, encanta, pulsa, "tem alma", diria João do Rio em A alma encantadora das ruas. Nesse sentido, a cidade não é apenas a depositária da vida moderna, mas é a própria metáfora de um imaginário que se queria moderno.

A cidade não deveria, então, ser vista apenas como um objeto de investigação, como um lugar essencial para entender a natureza das formas contemporâneas de sociabilidade e experiência: ela é também um dispositivo metafórico que marcou profundamente o desenvolvimento conceitual no Ocidente (Featherstone, 2000, p. 190).

Marcaria também o Brasil, cuja formação do contexto urbano dar-se-ia no Rio de Janeiro, essa metrópole psíquica, essa cidade que Gilberto Freyre chamaria de "panbrasileira".

\section{A formação da vida pública na cidade do Rio de Janeiro}

Para chegar a tal, o Rio de Janeiro precisou modificar a sua aparência. Na primeira metade do século XIX, acontecimentos econômicos transformaram a fisionomia do Brasil, como a decadência progressiva de lavouras tradicionais (cana-de-açúcar, algodão e tabaco), situadas no Norte, e a expansão da cultura do café, no Sul. Se, em princípios do século XIX, o país ainda ocupava uma posição modesta na exportação do café para os países do Ocidente, a partir da segunda metade 
do século XIX, o produto consolidou-se como o maior artigo de exportação brasileiro. Esse fato trouxe um progresso rápido para o Sul e Sudeste, beneficiando primeiramente o Rio de Janeiro, cidade cujo porto escoava o produto, tornando-se assim o principal centro financeiro e controlador do café. Mais tarde, as principais lavouras cafeeiras se deslocaram para o Oeste paulista, região de relevo e de clima mais adequados para o plantio, promovendo o crescimento da capital da província, São Paulo, o que acabou por gerar uma rivalidade, ainda em vigor, entre as duas grandes cidades.

À parte essas disputas internas, toda a região, conhecida por vale do Paraíba, firmou-se como o setor mais rico do país, isso graças unicamente ao café, que chegou a representar mais de 70\% das exportações brasileiras. Além de sua importância econômica, o produto foi responsável também pelos grandes acontecimentos sociais e políticos do país, como o surgimento da última grande aristocracia (depois da dos senhores de engenho e da dos grandes mineradores); o deslocamento das populações do Norte para o Sul; a imigração europeia; e a aceleração da abolição da escravatura. Seu grande auge foi a partir de 1860, quando promoveu o reajustamento da vida econômica brasileira, a ascensão no padrão de vida de certas classes e regiões e o aparelhamento técnico do país (surgimento de estradas de ferro, dos meios de comunicação, da mecanização de indústrias rurais, das primeiras manufaturas etc.). De acordo com Prado Júnior, em quem estamos nos baseando para fazer esta pesquisa, “[...] pode-se dizer que é nesta época que o Brasil tomara pela primeira vez conhecimento do que fosse o progresso moderno e uma certa riqueza e bem-estar material" (Prado Júnior, 1976, p. 168).

A abolição do tráfico negreiro, em 1850, também fora decisivo para isso, liberando capitais antes investidos nessa atividade para outros empreendimentos, como bancos, empresas, ferrovias, companhias de navegação a vapor, de transporte urbano e de gás. Para Prado Júnior (1976), o progresso do período, em termos relativos, foi o mais acelerado do que qualquer outro momento posterior. Obviamente que tal processo mesclou-se com a já consolidada sociedade agrária, dividida entre fazendas e portos, senhores e escravos. 
Essa antiga ordem social, fruto de uma sociedade latifundiária voltada para o mercado internacional, conviveu com um incipiente capitalismo que promoveu o início de um processo de concentração de capitais, facilitado pela inflação de créditos, pelas emissões de papel-moeda e pela especulação. Sintoma disso foi a multiplicação de empresas financeiras, como bancos, companhias de seguros, negócios de bolsas, que imitavam as grandes praças financeiras da Europa e dos Estados Unidos. A imitação foi além da atividade financeira, recaindo também na transformação dos espaços públicos e no modo de vida dos cidadãos.

A nova burguesia esforçava-se então para copiar os padrões de vida e o ritmo financeiro da economia europeia e, segundo Sevcenko (1983, p. 30), quatro princípios regeram essa metamorfose no Rio de Janeiro: a condenação de hábitos e costumes ligados à sociedade tradicional; a negação de elementos da cultura popular que maculassem a imagem de sociedade civilizada; a expulsão de grupos populares da área central; e um cosmopolitismo identificado com a vida parisiense.

Essa identificação se traduz em novas edificações e na urbanização da cidade que, imitando a Paris burguesa e neoclássica, erigiu palácios majestosos, edifícios monumentais e avenidas amplas. Surgiram outras novidades, como o calçamento com paralelepípedos, a arborização, a rede de esgoto e o abastecimento de águas nas casas. Em Esaú e Jacó (1904), Machado de Assis (2002, p. 130) registra essa "epopeia de ouro" na cidade do Rio de Janeiro:

A capital oferecia ainda aos recém-chegados um espetáculo magnífico. Vivia-se dos restos daquele deslumbramento e agitação, epopéia de ouro da cidade e do mundo, porque a impressão total é que o mundo inteiro era assim mesmo. [...] Eram estradas de ferro, bancos, fábricas, minas, estaleiros, navegação, edificação, exportação, importação, ensaques, empréstimos, todas as uniões, todas as regiões, tudo o que esses nomes comportam e mais o que esqueceram.

[...] Pessoas do tempo, querendo enxergar a riqueza, dizem que o dinheiro brotava do chão, mas não é verdade. Quando muito, caía do céu. 
Mas, juntamente como toda essa revolução nos aspectos da cidade, a capital experimentava também uma fase de especulação cambial, agiotagem e falso luxo, esse último presente na imitação do estilo europeu das roupas, da música, das danças de salão, da mobília doméstica, do idioma e da literatura. Afinal, com a implantação do novo ideário financeiro nascido com a República, era necessário também remodelar os hábitos nacionais, importando não apenas o comércio, mas qualquer produção cultural ou "novidade" proveniente do Velho Mundo. A descrição que Machado (1955, p. 44) faz do personagem Mendonça, de Helena ( 1876), revela a importância da moda parisiense no cenário local, recuperando dois signos da modernidade estrangeira:

Vestia com o maior apuro, como verdadeiro parisiense que era, arrancado de fresco ao grand boulevard, ao café Tortoni e às récitas do Vaudeville. A mão larga e forte calçava fina luva cor de palha, e sobre o cabelo, penteado a capricho, pousava um chapéu de fábrica recente (Machado de Assis, 1955, p. 44).

Além de os navios europeus, sobretudo os franceses, transportarem mobiliário, artigos de luxo e figurinos da moda, eles traziam também escolas filosóficas dominantes, notícias sobre peças, livros em voga e modelos de comportamento.

Um desses modelos foi, sem dúvida, o hábito de se passear nas ruas.

Assim, por mais que não pudéssemos ignorar a peculiaridade da constituição da nossa identidade nacional, engendrada pelo papel do regime escravista numa civilização que se queria moderna e pelas relações de proteção e favor característicos do patriarcado rural, o fato é que havia um afã europeizante muito forte nos costumes brasileiros do período que se manifestava de várias formas (no urbanismo, nas modas, no comércio, no idioma, no comportamento etc.) e que forneciam os signos para a atmosfera de Civilização e para a distinção e a superioridade da elite carioca. O Rio passou a ditar não só as novas modas e comportamentos, mas, acima de tudo, os sistemas de valores, o modo de vida, a sensibilidade, o estado de espírito e as disposições pulsionais que articulam a modernidade como uma experiência existencial íntima (Sevcenko, 1998, p. 522). 
Portanto, se as ideias não estão exatamente no lugar no que se refere à importação do ideário burguês pelo Brasil, há sinais de uma tentativa de aproximar-se dele, em que pese o seu caráter postiço, falso, dentro de uma realidade tão desigual. Tal tentativa se faria presente nos costumes, no urbanismo, na língua, nas modas, na literatura e no costume de ir às ruas. Abriu-se um campo novo de experiências no seio da cidade apesar do atraso e da ambivalência com que fora sentido no Brasil.

\section{A crônica como uma narrativa urbana}

Se até aqui focamos a análise no processo histórico, levando em conta as transformações econômico-sociais da construção do movimento de ocupação da cidade do Rio de Janeiro na passagem entre dois séculos, cabe agora levar em conta as pequenas histórias. Ou como diz Machado por meio do personagem Brás Cubas:

Quem não sabe que ao pé de cada bandeira grande, pública, ostensiva, há muitas vezes várias outras bandeiras modestamente particulares, que se hasteiam e flutuam à sombra daquela, e não poucas vezes lhe sobrevivem? Mal comparando, é como a arraia-miúda, que se acolhia à sombra do castelo feudal; caiu este e a arraia ficou (Machado de Assis, 1992, p. 23).

Ou para usar a perspectiva de Rocha e Eckert (2005, p. 95), mesmo considerando-se a feição macroscópica da configuração da geografia urbana do Brasil, faz-se no necessário deslocar

[...] o foco de análise da descrição realista da cidade na história para um conhecimento compreensivo da cidade segundo os acontecimentos anódinos que ocorrem no seu interior e a efervescência que rege a vida ordinária de seus habitantes.

E aí a importância das narrativas miúdas que assumem um lugar estratégico para a reflexão antropológica:

Nas grandes metrópoles, a vida humana torna-se objeto principal de estudo pelos "retalhos, os resíduos", "secundário ou excêntrico": a moda, o jogo, o colecionador, 
os dioramas, a prostituição, o flâneur, as passagens, o interior, as ruas, a fotografia, o réclame (Rocha e Eckert, 2005, p. 83, grifos das autoras).

A crônica é, sem dúvida, um desses resíduos. Marlyse Meyer (apud Candido et al., 1992, p. 93-133), tentando traçar uma cronologia do gênero, ressalta o seu caráter difuso. Segundo ela, no começo do século XIX, le feuilleton designava o rodapé da primeira página dos jornais, espaço destinado ao entretenimento e onde valia tudo: contar piadas, propor charadas, oferecer receitas. De espaço vale-tudo, passa, em finais de 1830, a publicar ficção em fatias, com enorme benefício financeiro para os jornais. Mas é no corpo interno do Jornal do Comércio, sob a rubrica de Variedade, que, em fins de 1830, passa-se a publicar aquilo que viria a dar na crônica: conteúdos variados, matérias traduzidas, resenhas, ficções curtas, poesias, lista de traduções etc. O romance-folhetim, "avô de todas as nossas novelas", continuaria a ocupar o rodapé da página um. Em ambos os casos, folhetim-variedade ou romance-folhetim, alguns escritores, ao terem que traduzir ou escrever "a toque de caixa" pelo novo imperativo da velocidade do meio jornal, transpuseram esse modo de escrita para o seu posterior texto de ficção, o que comprova a simbiose estabelecida nesse momento de transição, via folhetim ou crônica, entre a literatura e o jornalismo.

Adotando o tom ligeiro, miúdo, da fala cotidiana, a crônica passou a incorporar também um toque de humor, libertando-se, enfim, do folhetim e passando a ter vida própria, sendo esse um momento crucial para o seu amadurecimento.

Com o romance-folhetim, o livro é então seccionado para a produção em série do jornal. Mas, enquanto o romance-folhetim tem ainda os olhos voltados para o interior burguês, a crônica já nasce no "olho" da rua e com os olhos voltados para a rua. Para as mínimas histórias da rua, e sua forma revela essa perspectiva estilhaçada. O texto sofre fraturas, encurta-se, desmembra-se para caber nas páginas volantes e voláteis do jornal. Nesse contexto, os fragmentos de texto, as ruínas, adquirem importância fundamental. Borinski, citado por Benjamin (1984, p. 200) em Origem do drama barroco alemão, declarou, a respeito da forma como os alegoristas barrocos reapropriavam-se das ruínas: 
A fachada partida, as colunas despedaçadas têm a função de proclamar o milagre de que o edifício em si tenha sobrevivido às forças elementares da destruição, do raio, e do terremoto. Em sua artificialidade, essas ruínas aparecem como último legado de uma Antigüidade que no solo moderno só pode ser vista, de fato, como um pitoresco monte de escombros.

Quando o palácio do livro se estilhaçou sob o olhar do espectador moderno, seus fragmentos produziram pequenas partículas volantes, histórias mínimas, uma literatura menor que fora se alojar, sem dor nem pesar, na morada portátil do jornal. Seu nome: crônica. Vestígio, entulho, ruína daquilo que era heterônomo, incompleto, despedaçado, leve demais, para que o livro a quisesse, a crônica proclama a primazia do fragmentário sobre o total, das pequenas histórias sobre a História total. "O falso brilho da totalidade se extingue [...]", diz Benjamin (1984, p. 200) a respeito da antinomia entre o Barroco e o classicismo. Em seu lugar: pedaço, fragmento, ruína. Porque sob a forma de ruína, "[...] a história não constitui um processo de vida eterna, mas de inevitável declínio". Ou seja, o fragmento subscrito na crônica significa o desmoronamento do palácio do livro como o destino de toda a construção humana.

Por isso a predileção da crônica pelos mínimos, como bem o revelara Bilac (apud Dimas, 1996, p. 19):

Os cronistas são como os bufarinheiros, que levam dentro das suas caixas rosários e alfinetes, fazendas e botões, sabonetes e sapatos, louças e agulhas, imagens de santos e baralhos de cartas, remédios para a alma e remédios para os calos, breves e pomadas, elixires e dedais (Gazeta de Notícias, 7 de fevereiro de 1904).

Ou sua predileção pelos restos:

Partindo do pressuposto de que o característico da sociedade é a produção de desperdícios, às vezes, reaproveitados (daí o asilo, o orfanato, o depósito de lixo), pode-se prever que a lógica implacável acabe transformando o conjunto do social numa simples acumulação de restos. 
Ora, se todo o resto é literatura, nenhum gênero mais apto do que a crônica para fixar a miscelânea do social (Antelo, 1989, p. 37).

Nada diz mais do sujeito alegórico do que o modo como Bilac vira o cronista. Os dois são correlatos. Porque é próprio do alegorês esvaziar os objetos de seu aspecto convencional cotidiano para lhes dotar de inusitados sentidos. A única possível significação do objeto é a que lhe é atribuída pelo alegorista. Para Benjamin, o detalhe está, em última análise, carregado sempre de história.

É na estética da crônica que o pormenor esvaziado do sentido cotidiano, catado no chão das ruas da grande metrópole, ressurge aos olhos do observador como material poético ou histórico. Ao incorporar o estilhaçamento do tempo, tanto na forma quanto nos assuntos que cata no chão, é digna de se configurar como um monumento da história. Um monumento que se despedaça, já uma ruína, subscrita não na história linear, feita de uma sucessão de etapas num tempo homogêneo, mas a história antilinear, cuja base é a descontinuidade, a ruptura, a catástrofe, em suma, um acúmulo de ruínas. A primeira é, segundo Benjamin, a história dos vencedores; a segunda, a dos vencidos. Cabe ao crítico, tal qual o alegórico barroco, a tarefa de reconstituir essas ruínas para que a vitória dos vencedores não seja definitiva. Portanto, a ruína tem um caráter ambivalente: ela alegoriza, ao mesmo tempo, o que foi destruído pelos opressores e, também, subjaz como testemunho "vivo" de que tudo está fadado à ruína.

A crônica como ruína mostra que a história nem sempre é feita apenas de medalhões e de dandies, mas também de naturezas subalternas. Ou como disse Brás Cubas, aproximando-se da descrição de Borinski a respeito das ruínas que insistem em sobreviver, tal qual os escombros, sob a destruição dos monumentos:

Quem não sabe que ao pé de cada bandeira grande, pública, ostensiva, há muitas vezes várias outras bandeiras modestamente particulares, que se hasteiam e flutuam à sombra daquela, e não poucas vezes lhe sobrevivem? Mal comparando, é como a arraia-miúda, que se acolhia à sombra do castelo feudal; caiu este e a arraia ficou (Machado de Assis, 1992, p. 23). 


\section{Habitantes da cidade: o flâneur, o cronista, o jornalista}

A crônica foi, então, a forma oportuna de passagem entre a Literatura e o Jornalismo, subscrevendo um novo estilo, contaminado pelo enquadramento fragmentário da diagramação das folhas, pela pressão dos horários, pela velocidade da própria movimentação das rotativas e em sincronia com os assuntos gerados pelas ruas cada vez mais movimentadas. Por sua inerente ambivalência, a crônica constitui-se no arquétipo apropriado que equivaleria ao que Saint-Hilaire (apud DaMatta, 1987, p. 56) constatou ao descrever a varanda, espaço intermediário entre a casa e a rua:

A gente abastada tem o cuidado de reservar na frente de sua casa uma galeria ou varanda, formada pelo teto que se prolonga além das paredes, e é sustentado por colunas de madeira. Fica-se geralmente nestas galerias e, em todas as estações, aí se respira um ar fresco, igualmente ao abrigo da chuva e do ardor solar.

E nesta zona de passagem espreita-se e comenta-se a rua:

Não posso dizer positivamente em que ano nasceu a crônica; mas há toda a probabilidade de crer que é coletânea das primeiras duas vizinhas. Essas vizinhas, entre o jantar e a merenda, sentaram-se à porta para debicar os sucessos do dia. Provavelmente começaram a lastimar-se do calor. Uma dizia que não pudera comer ao jantar, outra que tinha a camisa mais ensopada do que as ervas que comera. Passar das ervas às plantações do morador fronteiro, e logo às tropelias amatórias do dito morador, e ao resto, era a coisa mais fácil, natural e possível do mundo. Eis a origem da crônica (Folha de $S$. Paulo, 1994, p. 13-15)

Lendo a crônica como uma metáfora da varanda, diríamos dela que é essa zona de contemplação do espaço urbano, que tira o pé do território do livro (a casa da palavra) para se aventurar no espaço arruado do jornal. A crônica personifica na forma o esquartejamento dos sentidos do habitante da cidade, que tem sua maneira de olhar alterada pelo movimento apressado do passo, dos transportes públicos, das vitrines, dos letreiros, dos assuntos modernos que se produzem no 
bojo da rua. "Naturalmente, cansadas as pernas, meto-me no primeiro bonde, que pode trazer-me à casa ou à Rua do Ouvidor, que é onde todos moramos [...]", escreveu Machado em A Semana do dia 2 de janeiro de 1889. Ali, "[...] onde a vida passa um burburinho de todos os dias e de cada hora. Chovem assuntos modernos" (Gledson, 1996, p. 190).

Tal qual o flâneur Machado que mora agora na rua, a crônica passeia pela cidade e, para além de incorporar o movimento e a fragmentação do olhar na sua própria forma, procura tematizar, catalogar os assuntos para torná-los menos assustadores aos habitantes na metrópole. Procedimento análogo ao descrito por Benjamin sobre a "literatura panorâmica" que também teve seu auge no século XIX em Paris. Dentro desse gênero havia os fascículos em formato de bolso chamados de "fisiologias", que se ocupavam da descrição de tipos humanos que circulavam nas feiras de Paris. Mais tarde, dedicar-se-iam à consagração da cidade, perfilando suas ruas, seus panoramas, onde tudo "passava em desfile" e a vida pequeno-burguesa era passada em revista. Segundo Benjamin (1994, p. 34), a calma dessas descrições combinaria com o jeito do flâneur, que fazia "botânica no asfalto". Esse e outros gêneros (como o melodrama que desembocaria na notícia de fait-divers ou o romance policial, cujo conteúdo é a eliminação dos vestígios do indivíduo na multidão da metrópole) são tentativas de aplacar os riscos e as ameaças da vida nas grandes cidades, dissecando-as, trazendo à luz seus becos e profundezas escuras. Dissecando a cidade, mapeando seu traçado, trazendo à luz a sua face oculta, eles aplacavam a ameaça subscrita no território estrangeiro que era, até então, o espaço da rua.

Se não se pode "[...] transformar a casa na rua e nem a rua na casa impunemente [...]" (DaMatta, 1987, p. 59), diríamos que o cronista o faz sem parcimônia. Ele é o equivalente do flâneur, tipo que tem sua origem na Paris do início do século XIX quando se construíram cerca de 30 galerias na cidade. Benjamin, que formulou um estudo sobre esse tipo, descreveria as galerias como caminhos cobertos de vidro e revestidos de mármore, por meio de blocos de casas, onde, de ambos os lados dessas vias, estendem-se os mais elegantes estabelecimentos comerciais, como se fosse um mundo em miniatura. Tal qual a varanda 
e a crônica, as galerias são um meio-termo entre a rua e o interior da casa.

Fazer essa travessia perigosa é tanto tarefa do flâneur quanto do cronista, o primeiro jornalista moderno. O próprio Benjamin declararia que "[...] a base social da flânerie é o jornalismo. É como flâneur que o literato se dirige ao mercado para se vender". Sua força de trabalho é o tempo que gasta na contemplação dos bulevares. As novas experiências na cidade são a sua matéria-prima. O espetáculo da cidade o inebria e converte-se em mercadoria para consumo dessa massa por meio das páginas volantes do jornal. Se a moldura do livro ainda corresponde à armação do interior burguês, a massa, parodiando Benjamin, só exerceria seu direito à cidade pelo jornal, veículo que passa por ruas, recolhendo notícias e tipos, retratando o tempo difuso e as teias de uma rede social contraditória. A "maneira de ser" do jornal vai além de descrever os ares dos tempos, mas enquanto se produz já é o tempo que se infiltra tal qual ruína, tal qual estilhaço, do esfacelamento da antiga morada livresca, essa tão fechada como os interiores burgueses. Ele atravessa a cidade alegorizando a sua face heterogênea, pela justaposição, pelo uso da montagem contra a narrativa linear do livro. Em suas páginas toda a representação da cidade partida com seus percursos aleatórios, seus recortes, seus "hipertextos", sua fragmentação e distração do olhar.

A cidade moderna e os novos meios de comunicação de massa ajudaram a mudar o olhar estético da contemplação para a distração. A mobilidade do olhar e as oscilações entre imersão e afastamento ajudam a desenvolver uma atitude na qual a paisagem urbana passa a ser percebida como fragmentada e alegórica, ao mesmo tempo em que a vida cotidiana sofre um processo de estetização. A muito comentada natureza distraída da experiência moderna tem, portanto, seu precursor no olhar móvel do flâneur (Featherstone, 2000, p. 195).

Tal qual o flâneur, o jornalista é, antes de tudo, um habitante da cidade:

O mundo urbano tem características e particularidades que se expressam no jornalismo. Quando Georg Simmel 
(1979) cita o anonimato, as relações transitórias e a superficialidade como aspectos dos indivíduos urbanos, não se pode deixar de associar essas características ao jornalista. O jornalista experimentará no seu cotidiano a cidade como espaço da diversidade, do cruzamento de mundos e "tribos" diferentes, desvendando territórios heterogêneos e construindo, assim, um mapa, para muitos habitantes, desconhecido (Travancas, 2010, p. 123).

Como se vê, tanto o flâneur quanto o jornalista percorre a cidade, deixando-se tragar pelo coletivo.

As ruas são a morada do coletivo. O coletivo é um ser eternamente inquieto, eternamente agitado, que, entre os muros dos prédios, vive, experimenta, reconhece e inventa tanto quanto os indivíduos ao abrigo de suas quatro paredes. Para esse ser coletivo, as tabuletas das firmas, brilhantes e esmaltadas, constituem decoração mural tão boa ou melhor que o quadro a óleo no salão do burguês; os muros com 'défense d'afficher' (proibido colar cartazes) são sua escrivaninha, as bancas de jornal, suas bibliotecas, as caixas de correspondência, seus bronzes, os bancos, seus móveis do quarto de dormir, e o terraço do café, a sacada de onde observa o ambiente (Benjamin, 1994, p. 194).

A cidade é, então, recuperada pelo cronista. Ele age como um flâneur que, na acepção benjaminiana, é o poeta que vagueia pelas ruas urbanas lutando contra a dissolução da individualidade do sujeito e contra a perda da capacidade de olhar criticamente, recuperando para si a cidade.

Habitante de um universo privado de memória, o flâneur percorre as ruas desertas - na madrugada - quando a cidade volta a lhe pertencer, no momento em que julga descobrir seu passado - o da cidade e o seu próprio (Matos, 1989, p. 74).

Para João do Rio (2008, p. 32), o flâneur, que ele também chama de "pedestre da poesia da observação", é um ingênuo porque, "[...] conhecendo cada rua, cada beco, cada viela, sabendo-lhe um pedaço 
da história, [...], acaba com a vaga idéia de que todo o espetáculo da cidade foi feito especialmente para seu gozo próprio".

Habitar as ruas é, então, tarefa do cronista, o primeiro jornalista moderno. Aqui no Brasil, a crônica seria o gênero inaugurador que retrataria o fluxo de sujeitos e fatos pelas ruas da cidade. Afinal, diante de uma existência contraditória que oscila entre a segurança da casa burguesa e o fascínio mundano do "olho da rua", haveria de se criar um texto que ajustasse as duas pontas de sentimentos tão extremos. Um texto que passasse em revista a vida burguesa em seu footing diário, mas também a "marginália" proscrita que habitava as calçadas; que exaltasse os novos transportes públicos, mas que denunciasse os seus acidentes; que se encantasse com o que nela se ergue, mas se inquietasse com o que converte em ruína. Um texto que tivesse amor às ruas, que as consagrasse, que as dissecasse através de uma fisiologia da cidade inquietante. Uma escritura por natureza que olha para a rua e que se vende na rua. Uma literatura que habita a cidade, que se debruça sobre as ruínas da metrópole moderna por dentro. Porque é na metrópole moderna que se experimenta em seus extremos a fragmentação do olhar e o choque

A crônica abandonaria, então, a casa da palavra para deixar-se ir, volúvel e volátil, para o coração das ruas. Com o seu miúdo, documenta na forma e no que informa a fisiologia de um tempo em que o citadino vai às ruas deixar tragar-se pelo coletivo de uma cidade que se industrializa e documenta para além da história oficial uma mínima, porém vigorosa história.

\section{Notas:}

1 Jornalista pela Universidade Federal de Santa Catarina. Mestre e Doutora em Teoria Literária também pela Universidade Federal de Santa Catarina. Autora do livro $A$ Estética da Melancolia em Clarice Lispector e de artigos científicos para as revistas acadêmicas Estudos em Jornalismo, Mídia e Travessia, entre outras. Bolsista Capes-Reuni para pós-doutoramento no Programa de Pós-Graduação em Antropologia da UFSC. 


\section{Referências}

ANTELO, Raúl. João do Rio: o dândi e a especulação. Rio de Janeiro: TaurusTimbre, 1989.

BENJAMIN, Walter. Origem do drama barroco alemão. Tradução, apresentação e notas: Sergio Paulo Rouanet. São Paulo: Brasiliense, 1984.

. Charles Baudelaire: um lírico no auge do capitalismo. 3. ed. Tradução de José Carlos Martins Barbosa e Hemerson Alves Baptista. São Paulo: Brasiliense, 1994.

DAMATTA, Roberto. A casa e a rua: espaço, cidadania, mulher e morte no Brasil. Rio de Janeiro: Guanabara, 1987.

DIMAS, Antônio (Org.). Vossa insolência: crônicas/Olavo Bilac. São Paulo: Companhia das Letras, 1996.

FEATHERSTONE, Mike. O flâneur, a cidade e a vida pública virtual. In: ARANTES, Antonio (Org.). O espaço e a diferença. Campinas (SP): Papirus, 2000. p. 186-208.

FOLHA de São Paulo (Org.). Machado de Assis: crônicas escolhidas. São Paulo: Ática, 1994.

GLEDSON, John (Edição, introdução e notas). Bons Dias! crônicas ( 1888 1889) Machado de Assis. São Paulo: Hucitec, 1996.

JOÃO DO RIO. A alma encantadora das ruas. Rio de Janeiro: Companhia das Letras, 2008.

MACHADO DE ASSIS. Edição Jackson das Obras completas de Machado de Assis. Crônicas (1871-1878). São Paulo: Brasileira, 1955. (v. 3)

. Memórias póstumas de Brás Cubas. 3. ed. São Paulo: FTD, 1992. . Esaú e Jacó. 12. ed. São Paulo: Ática, 2002.

MARTIN-BARBERO, Jesús. Dos meios às mediações: comunicação, cultura e hegemonia. Tradução de Ronald Polito e Sérgio Alcides. Rio de Janeiro: Editora UFRJ, 2009.

MATOS, Olgária C. F. Os arcanos do inteiramente outro: a Escola de Frankfurt, a melancolia e a revolução. 1. ed. São Paulo: Brasiliense, 1989.

. O iluminismo visionário: Benjamin, leitor de Descartes e Kant. São Paulo: Brasiliense, 1993.

MEYER, Marlyse. Voláteis e versáteis. De variedades e folhetins se faz a chronica. In: CANDIDO, Antonio et al. A crônica: o gênero, sua fixação e suas transformações no Brasil. São Paulo: Editora da UNICAMP; Rio de Janeiro: Fundação Casa Rui Barbosa, 1992. p. 93-133. 
MORIN, Edgar. Cultura de massas no século XX: o espírito do tempo - 2: necrose. Rio de Janeiro: Forense-Universitária, 1977.

PRADO JÚNIOR, Caio. História econômica do Brasil. 37. ed. São Paulo: Brasiliense, 1976.

ROCHA, Ana Luiza Carvalho da; ECKERT, Cornélia. O tempo e a cidade. Porto Alegre: Editora da UFRGS, 2005.

SEVCENKO, Nicolau. Literatura como missão: tensões sociais e criação cultural na Primeira República. 3. ed. São Paulo: Brasiliense, 1983.

SEVCENKO, Nicolau. História da vida privada no Brasil. São Paulo:

Companhia das Letras, 1998. v. 3

TRAVANCAS, Isabel Siqueira. O mundo dos jornalistas. 4. ed. São Paulo: Summus, 2011.

Recebido em 05/09/2012

Aceito em 10/10/2012 